DEVELOPMENT OF A CALCIUM-BASED SORBENT FOR HOT GAS CLEANUP

Semi-Annual Technical Progress Report

October 1, 1996 - March 31, 1997

T. D. Wheelock, L. K. Doraiswamy, and K. Constant

Principal Investigators

T. Akiti and J. Zhu

Graduate Assistants

Issued: March, 1997

DOE Grant No. DE-FG22-96PC96203

Chemical Engineering Department and

Center for Coal and the Environment

2114 Sweeney Hall

Iowa State University

Ames, Iowa 50011-2230 


\section{DISCLAIMER}

This report was prepared as an account of work sponsored by an agency of the United States Government. Neither the United States Government nor any agency thereof, nor any of their employees, makes any warranty, express or implied, or assumes any legal liability or responsibility for the accuracy, completeness, or usefulness of any information, apparatus, product, or process disclosed, or represents that its use would not infringe privately owned rights. Reference herein to any specific commercial product, process, or service by trade name, trademark, manufacturer, or otherwise does not necessarily constitute or imply its endorsement, recommendation, or favoring by the United States Government or any agency thereof. The views and opinions of the authors expressed herein do not necessarily state or reflect those of the United States Government or any agency thereof. 


\title{
DEVELOPMENT OF A CALCIUM-BASED SORBENT FOR HOT GAS CLEANUP
}

\author{
Semi-Annual Technical Progress Report
}

October 1, 1996 - March 31, 1997

T. D. Wheelock, L. K. Doraiswamy, and K. Constant Principal Investigators

\begin{abstract}
Work has started on the development of a superior calcium-based sorbent for use in hot gas cleanup in IGCC systems. The aim is to develop a sorbent which will remove $\mathrm{H}_{2} \mathrm{~S}$ and COS from hot coal gas and be capable of repeated loading and regeneration. Porous alumina pellets and other porous refractory materials will be impregnated with calcium to prepare sorbents for testing. A preliminary review of the literature suggests that such materials have not been investigated extensively for cleaning coal gas.
\end{abstract}




\section{TABLE OF CONTENTS}

Page

Executive Summary 1

Introduction 2

$\begin{array}{lr}\text { Results and Discussion } & 2\end{array}$

$\begin{array}{lr}\text { Conclusions } & 9\end{array}$

$\begin{array}{lr}\text { References } & 9\end{array}$ 


\section{EXECUTIVE SUMMARY}

The main objective of this project is the development of a superior calcium-based sorbent for use in hot gas cleanup in IGCC systems. The sorbent should be capable of removing all but traces of $\mathrm{H}_{2} \mathrm{~S}$ and COS from hot coal gas and should withstand repeated loading and regeneration. Initially, the focus will be on utilizing porous substrates such as porous alumina pellets which can be impregnated with calcium. Several potential substrates have been collected and are being characterized by various techniques. Also different methods for infusing the substrates with calcium are being tested.

A preliminary review of the technical literature has revealed only a few publications which deal with synthesis of calcium-based sorbents that are designed specifically for removing $\mathrm{H}_{2} \mathrm{~S}$ from hot gas streams. 


\section{$\underline{\text { INTRODUCTION }}$}

This is a new research project which is directed towards the development of a superior calcium-based sorbent for hot gas cleanup in integrated coal gasification, combined-cycle (IGCC) systems for generating electric power. The goal will be the development of a rugged and regenerable sorbent which is capable of removing all but traces of hydrogen sulfide from coal gas at temperatures in the range of 1075 to $1325^{\circ} \mathrm{K}$ $\left(1470\right.$ to $\left.1920^{\circ} \mathrm{F}\right)$.

Two general methods will be used for creating potential sorbents. One method will impregnate porous refractory pellets (e.g., porous alumina pellets) with micrometer size crystals of calcium oxide. Another method will employ high temperature solid state reactions to produce porous composites such as $\mathrm{CaO} \cdot \mathrm{Ca}_{2} \mathrm{SiO}_{4}$. Various methods will be used for characterizing and testing the materials.

The initial effort has involved reviewing a large body of technical literature and collecting and characterizing potential porous substrates which can be impregnated with calcium oxide.

\section{$\underline{\text { RESULTS AND DISCUSSION }}$}

\section{$\underline{\text { Literature Review }}$}

A computerized search of the technical literature for publications dealing with calcium-based sorbents for sulfurous gases was conducted using the Chemical Abstracts

data base for the period from 1967 to the present. By limiting the search to the following categories and key words, the search produced 66 references which might prove relevant:

1. Sorbent 
2. Lime, limestone, calcium

3. Hydrogen sulfide

Abstracts corresponding to these references were obtained from the same data base. An examination of the abstracts showed that many of the publications dealt with the use of limestone, dolomite, and the calcined products of these materials as sorbents for hydrogen sulfide. Only a small number of publications dealt with sorbents derived by combining calcium compounds with other materials to improve sorbent properties.

Among the more recent papers concerned with the development of a calciumbased sorbent with improved properties was that of Christoforou, et al. (1). These workers used a dry impregnation technique to impregnate a porous magnesia substrate with calcium oxide particles which produced a sorbent containing 7.0 to 8.5 wt.\% $\mathrm{CaO}$. Unfortunately, the technique was not described. For some tests the sorbent was treated first with methanol to increase the surface area and pore volume of the material. The sorbents were tested at $600^{\circ} \mathrm{C}$ in a small fluidized bed reactor supplied with $0.2 \% \mathrm{H}_{2} \mathrm{~S}$ in nitrogen. The $\mathrm{CaO}$ utilization of the methanol-treated sorbent was more than four times that of the untreated sorbent. Regeneration of the spent sorbents at $550-670^{\circ} \mathrm{C}$ with different gas mixtures produced varying results depending on gas composition. No information was presented concerning the attrition resistance of the materials.

Several patents describe methods of producing improved calcium-based sorbents. One method is a sol-gel process that produces an alumina-containing support doped with calcium which is claimed to remove $\mathrm{H}_{2} \mathrm{~S}$ from gas mixtures (2). The process is claimed to produce $3 \mathrm{~mm}$ diameter spherical particles which have a large surface area and high crushing strength. 
Another method of producing a sulfur sorbent involves impregnating a preformed porous refractory support with an aqueous solution of a calcium salt followed by drying and calcining the resulting material (3). It is claimed that any of the following materials can be used as a support: alumina, silica, titania, zirconia, aluminosilicates, aluminophosphates, and mixtures thereof. An alternate method of production is also claimed whereby the supporting material is peptized to form a plastic mass which is mulled with a calcium compound and then extruded, dried, and calcined.

Another method, which is claimed to produce an attrition resistant, highly reactive limestone-based sorbent, involves binding limestone particles with a material such as attapulgite clay which is stable at high temperature (4). Fine particles of limestone and binder are dry-blended, and then water is added to form a paste which is subsequently agglomerated with a pin mixer or pug mill. The agglomerates are subsequently dried and calcined.

Still another method of preparation involves mixing fine particles of limestone, asbestos, and borax with sodium silicate and subsequently granulating the mixture (5). The granules are heated to $190-450^{\circ} \mathrm{C}$ and used as a sorbent.

While the preceding patents contain little information concerning the effectiveness and durability of the sorbents produced by the respective methods, there is considerable information about a calcium silicate type of sorbent for $\mathrm{H}_{2} \mathrm{~S}$ which was prepared by agglomerating type III Portland cement (6). A drum pelletizer was used to prepare spherical agglomerates in the 1 to $3 \mathrm{~mm}$ size range by spraying water onto the cement powder. The freshly prepared agglomerates were very fragile and had to be cured for 16$18 \mathrm{hr}$ before they could be handled. After curing for 28 days in an atmosphere of $100 \%$ 
humidity, the pellets contained $25-35$ wt.\% water and were strong. In a TGA experiment conducted at 950 to $1000^{\circ} \mathrm{C}$ with a gas mixture containing $0.5 \% \mathrm{H}_{2} \mathrm{~S}, 12.5 \% \mathrm{CO}, 12.5 \%$ $\mathrm{H}_{2}$, and $8.0 \% \mathrm{CO}_{2}$, over $30 \%$ of the available $\mathrm{CaO}$ content of the sorbent appeared to be converted in $2 \mathrm{hr}$ by the reaction,

$$
(\mathrm{CaO})_{3} \mathrm{SiO}_{2}+3 \mathrm{H}_{2} \mathrm{~S}=(\mathrm{CaS})_{3} \mathrm{SiO}_{2}+3 \mathrm{H}_{2} \mathrm{O}
$$

Subsequent regeneration with $15 \% \mathrm{CO}_{2}$ in $\mathrm{N}_{2}$ at $1000^{\circ} \mathrm{C}$ was complete in $1 \mathrm{hr}$ as a result of the following reaction:

$$
(\mathrm{CaS})_{3} \mathrm{SiO}_{2}+9 \mathrm{CO}_{2}=(\mathrm{CaO})_{3} \mathrm{SiO}_{2}+3 \mathrm{SO}_{2}+9 \mathrm{CO}
$$

Repeating the sulfidation/regeneration cycle four times did not seem to affect the capacity of the sorbent. Further sulfidation and regeneration tests were conducted with a small fluidized bed reactor. For these tests, some of the pellets were crushed and screened to produce a sorbent with a particle size range of 0.15 to $0.84 \mathrm{~mm}$. When this material was fluidized with a gas mixture similar to that used in the TGA experiment except that the $\mathrm{H}_{2} \mathrm{~S}$ concentration was increased to $0.85 \%$, no $\mathrm{H}_{2} \mathrm{~S}$ was detected in the off-gas until $25 \%$ of the available $\mathrm{CaO}$ in the sorbent was utilized. Furthermore, the particles appeared to be highly attrition resistant.

This brief review indicates that the synthesis of calcium-based sorbents for $\mathrm{H}_{2} \mathrm{~S}$ has been limited. Also a cursory examination of the literature indicates that much more work has been devoted to the development of calcium-based sorbents for sulfur oxides. Since a calcium-based sorbent is as likely to adsorb $\mathrm{H}_{2} \mathrm{~S}$ as $\mathrm{SO}_{\mathrm{x}}$, the literature dealing with development of sorbents for sulfur oxides will need to be reviewed in the future. 


\section{Porous Substrates}

A number of porous materials are being collected which show promise as substrates to be impregnated with calcium oxide. The materials which have been received to date are listed in Table 1. Although alumina is the predominant material, other materials are also being collected for evaluation. It can be seen that the samples supplied by Alcoa have a very large surface area which suggests that their pore size is very small. On the other hand, the samples supplied by Hi-Tech Ceramics have a very large pore size which probably means that they have a small surface area.

The substrates are being characterized by the methods shown in Figure 1. First the density, pore volume, surface area, and pore size and shape of the clean substrate are

Table 1. Porous substrates and their properties according to manufacturers.

\begin{tabular}{llcc} 
Substrate & Manufacturer & Surface Area, $\mathrm{m}^{2} / \mathrm{g}$ & ${\text { Pore Size, } \mathrm{ppi}^{\mathrm{a}}}^{\mathrm{a}}$ \\
\hline Alumina, DD431 & Alcoa & 343 & --- \\
Alumina, CL750 & Alcoa & 196 & --- \\
Alumina, DD831 & Alcoa & 339 & --- \\
Alumina, DD660 & Alcoa & 406 & --- \\
Alumina & Hi-Tech Ceramics & --- & 65 \\
Alumina & Hi-Tech Ceramics & --- & 45 \\
Alumina & Hi-Tech Ceramics & --- & 20 \\
Cordierite & Hi-Tech Ceramics & --- & 20 \\
Cordierite & Hi-Tech Ceramics & --- & 45 \\
Silica gel & Grace-Davison & --- & --- \\
\hline
\end{tabular}

${ }^{a}$ Pores per inch 


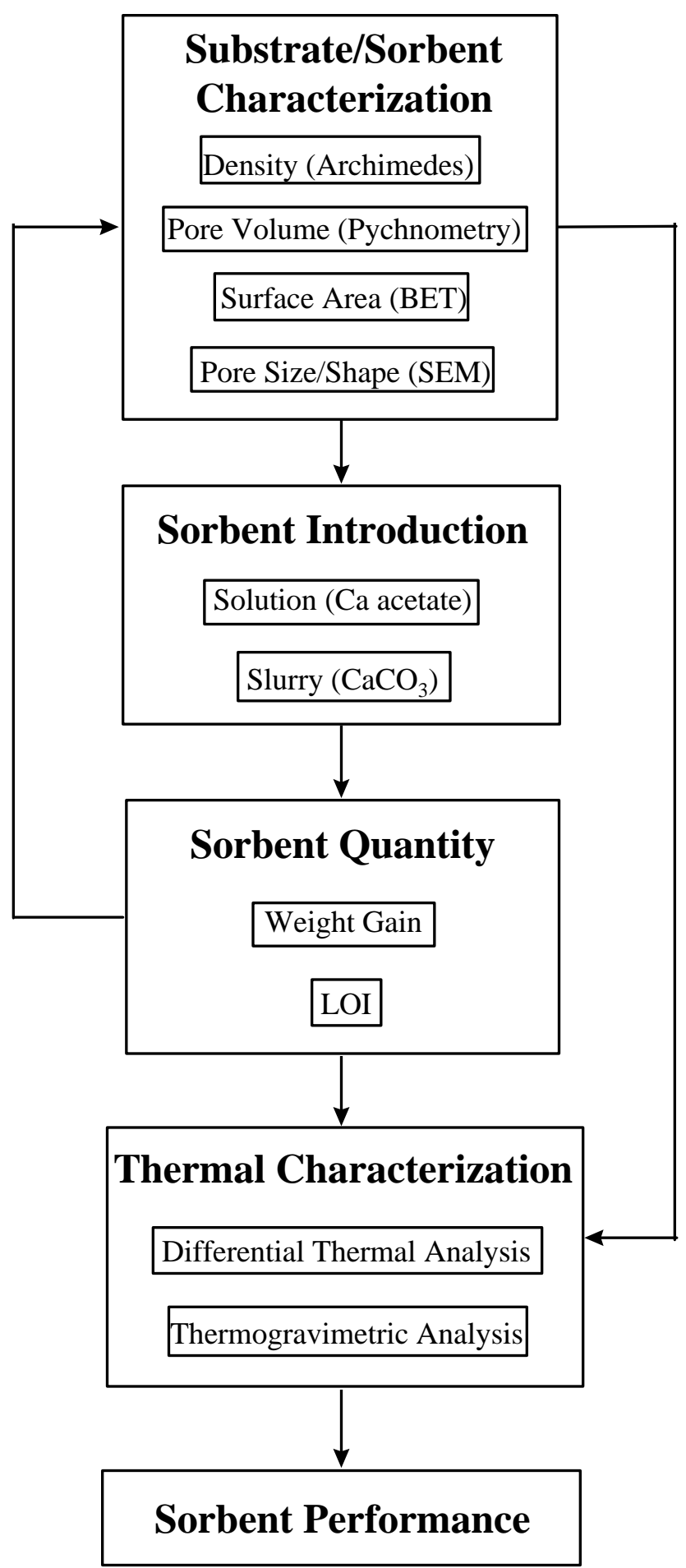

Figure 1. Scheme for producing and characterizing a calcium-based sorbent starting with a porous substrate. 
determined. The substrate may be further characterized by differential thermal analysis. Promising materials are impregnated with calcium by one of two methods. Materials with fine pores are repeatedly soaked in calcium acetate and dried. Materials with large pores are infiltrated with a calcium carbonate slurry. In either case, the quantity of sorbent is determined from the gain in weight on infiltration and the loss in weight on ignition. Differential thermal analysis is used to determine at what temperature the initial calcium compound is converted to $\mathrm{CaO}$. X-ray diffraction will be used to confirm the phases present.

As an example, preliminary characterization of DD431 alumina showed that the material has a surface area of $328 \mathrm{~m}^{2} / \mathrm{g}$ which agrees well with the manufacturer's claim of $343 \mathrm{~m}^{2} / \mathrm{g}$. Preliminary characterization also showed that the material has a bulk density of $1.38 \mathrm{~g} / \mathrm{cm}^{3}$ and porosity of 0.56 . Repeated soaking of this material in a concentrated solution of calcium acetate and drying at $150^{\circ} \mathrm{C}$ followed by calcination at $850^{\circ} \mathrm{C}$ for $12 \mathrm{hr}$ produced a product with $7.5 \% \mathrm{CaO}$. The performance of this material as a sorbent for $\mathrm{H}_{2} \mathrm{~S}$ will be determined by applying thermogravimetric analysis in the near future.

The characterization and testing of other substrates before and after infiltration with calcium will continue. Also the different infiltration techniques will be further refined to improve the calcium content and other properties of the sorbents. 


\section{CONCLUSIONS}

A review of the technical literature over the past 30 years has revealed a large number of publications which deal with adsorption of hydrogen sulfide by limestone, dolomite, and their calcination products. However, only a small number of publications have been found and reviewed which are concerned with the synthesis and application of improved calcium-based sorbents for hydrogen sulfide.

A number of porous materials have been collected which show promise as substrates for calcium-based sorbents. The substrates are being characterized and techniques are being developed for infusing the substrates with calcium.

\section{REFERENCES}

1. Christoforou, S. C., E. A. Efthimiadis, and I. A. Vasalos, Sulfidation-Regeneration Cycles of $\mathrm{ZnO}$ - and CaO-Containing Sorbents, Environmental Science \& Technology, 29, 372-383 (1995).

2. Frens, G., Sol-gel process for the manufacture of alumina-containing supports doped with an active component and/or its precursor, German Patent DE 4,114,924. (Chemical Abstracts: 116:87098; original unavailable for examination.)

3. Field, L. A., Process for removing sulfur from a hydrocarbon feedstream, S. African Patent ZA 8,604,295, July 23, 1987.

4. Voss, K. E., Limestone-based sorbent agglomerates for removal of sulfur compounds in hot gases and method of making, U.S. Patent 4,316,813, Feb. 23, 1982.

5. Bumbalek, A., Composites for separation of environmentally undesirable gases, especially sulfur oxides, hydrogen sulfide, and halogen acids from industrial waste gases, German Patent DE 2,459,272. (Chemical Abstracts: 87:89950; original unavailable for examination.)

6. Yoo, H. J. and M. Steinberg, Calcium Silicate Cement Sorbent for $\mathrm{H}_{2} \mathrm{~S}$ Removal and Improved Gasification Process, Final Report, DOE/CH/00016-1494, Brookhaven National Laboratory, Oct. 1983. 